\title{
Budget impact analysis of conversion from cyclosporine to sirolimus as immunosuppressive medication in renal transplantation therapy
}

This article was published in the following Dove Press journal:

ClinicoEconomics and Outcomes Research

17 October 2013

Number of times this article has been viewed

\author{
Naghmeh Foroutan' \\ Hamid R Rasekh' \\ Jamshid Salamzadeh' \\ Hamid R Jamshidi' \\ Mohsen $\mathrm{Nafar}^{2}$ \\ 'Department of Pharmacoeconomics \\ and Pharmaceutical Management, \\ School of Pharmacy, Shahid \\ Beheshti University of Medical \\ Sciences, ${ }^{2}$ Department of Kidney \\ Transplantation, Urinary Nephrology \\ Research Center (UNRC), Shahid \\ Labbafinejad Medical Center, Shahid \\ Beheshti University of Medical \\ Sciences, Tehran, Iran
}

Objectives: The aim of this study was to determine budget impact of conversion from cyclosporine (CsA) to sirolimus (SRL) in renal transplant therapy (RTT) from the perspective of insurance organizations in Iran.

Methods: An Excel-based model was developed to determine cost of RTT, comparing current CsA based therapy to an mTOR inhibitor-based therapy regimen. Total cost included both cost of immunosuppressive agents and relative adverse events. The inputs were derived from database of Ministry of Health and insurance organizations, hospital and pharmacy based registries, and available literature that were varied through a one-way sensitivity analysis. According to the model, there were almost 17,000 patients receiving RTT in Iran, out of which about 2,200 patients underwent the operation within the study year. The model was constructed based on the results of a local RCT, in which test and control groups received CsA, SRL, and steroids over the first 3 months posttransplantation and, from the fourth month on, CsA, mycophenolate mofetil (MMF), and steroids were used in the CsA group and SRL, MMF, and steroids were administered in the SRL group, respectively.

Results: The estimated cost of RTT with CsA was US $\$ 4,850,000$ versus US $\$ 4,300,000$ receiving SRL. These costs corresponded to the cost saving of almost US\$550,000 for the payers.

Conclusion: To evaluate the financial consequence of adding mTOR inhibitors to the insurers' formulary, in the present study, a budget impact analysis was conducted on sirolimus. Fewer cases of costly adverse events along with lower required doses of MMF related to SRL based therapies were major reasons for this saving budgetary impact.

Keywords: budget impact, renal transplantation, mTOR inhibitors, health insurance, out-of-pocket

\section{Introduction}

Renal transplantation has been considered a cost-effective alternative to other renal replacement therapies such as hemodialysis or peritoneal dialysis for patients suffering from end-stage renal disease (ESRD). ${ }^{1}$

Immunosuppressive drugs are major components of renal transplant therapy (RTT), which improve graft and patient survival. ${ }^{1}$ mTOR inhibitors are quite potent new immunosuppressive agents which modulate immune response in a way quite different from agents such as tacrolimus. ${ }^{2}$ Sirolimus (SRL) (Rapamune ${ }^{\circledR}$; Pfizer, Inc., New York, NY, USA) is an mTOR inhibitor obtained first US Food and Drug Administration (FDA) approval for kidney transplantation in 1999 having considered the successful Phase III clinical trial results ${ }^{3}$ and it provides effective maintenance therapy by decreasing common adverse events related to cyclosporine (CsA) such as nephrotoxicity, gingival hypertrophy, and hirsutism. ${ }^{4}$
Correspondence: Naghmeh Foroutan SDA Bocconi School of Management, Via Bocconi, 8, Milan 20136, Italy

Tel +39025836 6875

$\mathrm{Fax}+390258366890$

Email nforoutan88@gmail.com 
In 2006, a comprehensive meta-analysis study on advising mTOR inhibitors as a primary immunosuppression therapy was conducted by Webster et al. ${ }^{5}$ After considering different adverse events such as cardiovascular accident risks, cytomegalovirus (CMV) infection, and bone marrow suppression, they concluded that the benefit-harm trade-off of using mTOR inhibitors depended on patient groups. ${ }^{5}$ According to Büchler et al, an SRL based regimen with mycophenolate mofetil $\left(\right.$ CellCept $\left.^{\circledR}\right)$ was as effective as CsA based regimen in terms of graft and patient survival and maintaining low rate of acute rejection (AR). ${ }^{6}$ In 2011, Han et al reported considerable improvement in the long-term renal graft survival in Chinese patients through a 4-year period conversion from CsA into SRL. ${ }^{1}$ In general, a calcineurin inhibitor (CNI)-free regimen using SRL-MMF could achieve excellent renal function along with fewer AR episodes while experiencing a high rate of adverse events and drug discontinuation. ${ }^{6}$

In 2012, Nafar et al published a randomized controlled trial (RCT) in Iran, comparing immunosuppression effects of SRL versus CNI (CsA) based therapies among Iranian patients. One hundred patients from Shahid Labbafinejad Teaching Hospital were randomly selected and enrolled in the trial; they were then followed-up for 4 years (2004-2007) in this trial. ${ }^{7}$ In the present study, the above mentioned locally performed RCT is the reference clinical trial used to obtain health outcomes, probabilities, and resource utilization.

\section{Materials and methods}

The current study was performed in accordance with the report of International Society for Pharmacoeconomics and Outcomes Research (ISPOR) task force on good practice for Budget Impact Analysis (BIA) published in $2007 .{ }^{8}$

The analytic framework was designed according to results of the local RCT performed by Nafar et al (reference clinical trial). ${ }^{7}$ Consequently, an Excel ${ }^{\circledR}$ (Microsoft Corporation, Redmond, WA, USA) based model was constructed in which probabilities, health outcomes, and resource utilization were derived from the reference $\mathrm{RCT}^{7}$ as well as national and international literature and standard local guidelines in RTT.

In the present study, authors decided to define "health outcomes" as "adverse events" due to the fact that the main outcomes were treatment-related complications. Clinical data was obtained on the following key events: immunosuppressive drug use, graft failure, AR, CMV infection, hyperlipidemia, hypertension, and thrombocytopenia. Other adverse events which were quite similar in the two groups were excluded. Cost calculations were based on the standard tariffs for drugs and medical services used by
Iranian insurance organizations in making payments over the study year (2011-2012).

\section{Estimates of patient population and data sources}

Population-based incidence data were obtained from a central registry system in the Management Center for Transplantation and Special Diseases (MCTSD), affiliated with the Ministry of Health (MOH). ${ }^{9}$ Prevalence data were not considered in this study. Tariffs and expenditure data of RTT and dialysis were extracted from the databases of insurance organizations and hospital-based registries. Regarding required probabilities, apart from the reference RCT, hospital-based registries, local clinical trials, and related literature were reviewed. Estimates on out-patient details of the immunosuppressive regimen were obtained from Helal-e-Ahmar pharmacy records and databases of social security organizations (SSO). Health services (eg, physician or specialist visits, laboratory tests, nursing services, etc) and treatment options, which were similar in the two groups, were excluded. Model components and data sources have been summarized in Table 1.

According to MCTSD and insurance organizations' databases, the prevalence and incidence of ESRD were 357 per million population (pmp) and $66 \mathrm{pmp}$, respectively, and almost 17,000 patients received RTT in the study year (from March 2011 to March 2012), out of which about 2,200 patients (aged between 18-70 years old) had their renal transplantation operation over the mentioned time horizon.

There are two main semi-public hospitals in Tehran performing renal transplantation, which are in charge of almost half of kidney transplantation cases in the country $(25 \%$ at the Baghiatollah Hospital and 25\% at the Shahid Labbafinejad Hospital). The reference RCT was conducted in Shahid Labbafinejad Hospital, one of the major centers for renal transplantation in Iran with more than 550 transplantation cases per year. The hospital is the property of SSO, which is the largest insurance organization in Iran, and all the tariffs and guidelines are practically applied in exact accordance with the national standards under $\mathrm{MOH}$ supervision and regulations. To be in line with the reference RCT, only patients having their transplantation operation within the study year were included in the model $(n=2,200)$.

\section{Time horizon and perspective}

To make RTT and dialysis more affordable and accessible for eligible patients from all socioeconomic statuses, there are special facilities and reimbursement processes provided by the $\mathrm{MOH}$ as well as insurance organizations in Iran. There 
Table I Model inputs and data sources for the budget impact analysis

\begin{tabular}{|c|c|c|}
\hline Components & Unit cost & Source \\
\hline \multicolumn{3}{|l|}{ Immunosupressive therapy } \\
\hline - Cyclosporine (generic) & Price per tablet & Insurance organizations' database \\
\hline $\begin{array}{l}\text { - Mycophenolate mofetil } \\
\text { (Brand generic: Citogan }{ }^{\circledR} \text { ) }\end{array}$ & Price per tablet & Insurance organizations' database \\
\hline - Sirolimus (Rapamune ${ }^{\circledR}$ ) & Price per tablet & Helal-e-Ahmar pharmacy database \\
\hline \multicolumn{3}{|l|}{ Adverse events } \\
\hline \multicolumn{3}{|l|}{ - CMV } \\
\hline ○ Probability & - & $\begin{array}{l}\text { Literature, 3,6,12,13, (Nafar, } \\
\text { unpublished data, 20I2) }\end{array}$ \\
\hline \multicolumn{3}{|l|}{$\circ$ Treatment } \\
\hline Ganciclovir & Price per vial & Insurance organizations' database \\
\hline Hospitalization & Bed per night for posttransplant patients & $\begin{array}{l}\text { Accounting department database, } \\
\text { Shahid Labbafinejad Hospital }\end{array}$ \\
\hline \multicolumn{3}{|l|}{ - Acute rejection } \\
\hline - Probability & - & Nafar et $\mathrm{al}^{7}$ \\
\hline \multicolumn{3}{|l|}{$\circ$ Treatment } \\
\hline Methylprednisolon & Price per vial & Insurance organizations' database \\
\hline ATG & Price per vial & Insurance organizations' database \\
\hline Gancyclovir & Price per vial & Insurance organizations' database \\
\hline Hospitalization & Bed per night for posttransplant patients & $\begin{array}{l}\text { Accounting department database, } \\
\text { Shahid Labbafinejad Hospital }\end{array}$ \\
\hline \multicolumn{3}{|l|}{ - Graft failure } \\
\hline - Probability & - & Nafar et $\mathrm{al}^{7}$ \\
\hline \multicolumn{3}{|l|}{$\circ$ Treatment } \\
\hline Dialysis & Global tariff per operation & Insurance organizations' database \\
\hline Re-transplantation & Global tariff per operation & Insurance organizations' database \\
\hline \multicolumn{3}{|l|}{ - Hyperlipidemia } \\
\hline - Probability & - & $\begin{array}{l}\text { Literature, } 3,6,12,13,(\mathrm{Nafar} \\
\text { unpublished data, 20I2) }\end{array}$ \\
\hline \multicolumn{3}{|l|}{$\circ$ Treatment } \\
\hline Atorvastatin & Price per tablet & Insurance organizations' database \\
\hline \multicolumn{3}{|l|}{ - Hypertension } \\
\hline - Probability & - & $\begin{array}{l}\text { Literature, } 3,6,12,13 \text {, (Nafar, } \\
\text { unpublished data, 20I2) }\end{array}$ \\
\hline \multicolumn{3}{|l|}{$\circ$ Treatment } \\
\hline Amlodipine & Price per tablet & Insurance organizations' database \\
\hline \multicolumn{3}{|l|}{ - Thrombocytopenia } \\
\hline - Probability & - & $\begin{array}{l}\text { Literature, } 3,6,12,13 \text {, (Nafar, } \\
\text { unpublished data, 20I2) }\end{array}$ \\
\hline \multicolumn{3}{|l|}{$\circ$ Treatment } \\
\hline Plasmapheresis & Price per operation & Insurance organizations' database \\
\hline
\end{tabular}

Note: Rapamune ${ }^{\circledR}$; Pfizer, Inc., New York, NY, USA.

Abbreviations: CMV, cytomegalovirus; ATG, anti-thymocyte globulin.

are several governmental and quasi-governmental organizations engaged in ESRD issue: a) $\mathrm{MOH}$ as the main sponsor; b) SSO; c) Medical Service Insurance Organization (MSIO); d) Armed Forces Medical Service Organization (AFMSO); e) Imam Khomeini Relief Foundation (IKRF); and f) special organizations such as oil companies, radio and television broadcasters, and banks. ${ }^{10,11}$ In the current study, the model used the perspective of insurance organizations (mainly SSO, MSIO, AFMSO, and IKRF) with an annual number of about 17,000 patients receiving RTT relative to a 12-month time horizon while considering the following two assumptions:
1) tariffs for drugs and medical services were the same in all the considered insurance organizations, and 2) using SRL and CsA was stable throughout the period. Moreover, costs of care for patients were estimated based on the mean duration of treatment in the reference clinical trial. ${ }^{7}$

\section{Scenarios to compare}

According to the reference RCT conducted by Nafar et al, ${ }^{7}$ 100 kidney transplant recipients were randomly divided into two groups of 50 patients and received CsA, SRL, and steroids over the first 3 months posttransplantation and, from 
the fourth month on, CsA and SRL were replaced with mycophenolate mofetil (locally produced branded generic dosage form) in the SRL and CsA groups, respectively (Figure 1). Mean age \pm standard deviation in each group was $38.5 \pm$ 12.5 years and $42.5 \pm 14.3$ years in the SRL and CsA groups, respectively. After 3 years of follow-up, 36 patients remained in the SRL group and 28 patients in the CsA group. Two patients dropped out of the SRL group because of leucopenia and anemia and four patients died in the CsA group because of sepsis and cerebrovascular accident (CVA). One patient missed the follow-up in each group. According to the results of this study, biopsy proven AR (as the main health outcome followed in the study) occurred in nine patients in the CsA group (34 episodes) and in our patients (20 episodes) in the SRL group and thus the rate of AR in the CsA group was $1.7(34 / 20)$ fold higher than in the SRL group which corresponded to an incidence rate of almost $18 \%$ versus $8 \% \mathrm{AR}$ in the CsA and SRL groups, respectively, over 12 months posttransplantation. Rates of other adverse events were not published but registered in the follow-up database for a 1-year period of time from the transplantation operation. There was no statistically significant difference in graft and patient survival after 1-year between the two groups.

The costs and health outcomes (adverse events) were compared from the 4th month on, during which therapy regimens were different between the two groups (270 days was the duration of treatment).

\section{Cost of immunosuppressive agents}

The mean SRL dose was calculated based on the recommended dose of $2 \mathrm{mg} /$ day (two tablets per day) using the regulated market price for SRL of 10,000 Iranian Rials (IRR) (US\$0.82) for each tablet (US\$1.64 per patient per day).
The recommended dose for MMF administered along with SRL was $1 \mathrm{~g} /$ day, yielding almost 22,000 IRR (US\$1.79) per patient per day.

The mean CsA dose was $150 \mathrm{mg} /$ day per patient which was available in three dosages $(25,50$, and $100 \mathrm{mg}$ oral tablets). CsA cost was acquired from the insurance organizations' databases and, considering the total number of patients using each dosage (according to Helal-e-Ahmar pharmacy records), the cost of CsA per day was estimated as almost 5,700,000 IRR (US\$470). Cost of MMF in patients receiving CsA was almost double compared to the SRL administered group and prednisolone was the same dose and cost in both groups (Table 2).

\section{Cost of adverse events}

Major adverse events were taken into account for SRL versus CsA during 12 months after transplantation, which were mainly AR ( $8 \%$ versus $18 \%),{ }^{7}$ thrombocytopenia (45\% versus $8 \%$ ), hyperlipidemia (44\% versus $14 \%$ ), hypertension $(78 \%$ versus $67 \%)$, CMV infection $(6 \%$ versus $23 \%),{ }^{3,6,12,13}$ and graft failure $(7.5 \%$ versus $10.5 \%)$, respectively. ${ }^{7}$ Regarding CMV infection, ganciclovir was administered over a 7-day hospitalization with an average treatment dose of $5 \mathrm{mg} / \mathrm{kg}$ every 12 hours. In the case of AR episodes, methylprednisolone (with daily boluses of 250-1000 mg), antithymocyte globulin (ATG) with a daily dose of $10-20 \mathrm{mg} / \mathrm{kg}$, and ganciclovir for CMV infection prophylaxis ( $5 \mathrm{mg} / \mathrm{kg}$ every 24 hour until hospitalization) were administered in renal transplant recipients. Other adverse events, their treatment details and related cost per each individual patient, are summarized in Table 3. Total cost of adverse events and a comparison between SRL and CsA based regimens is shown in Table 4.

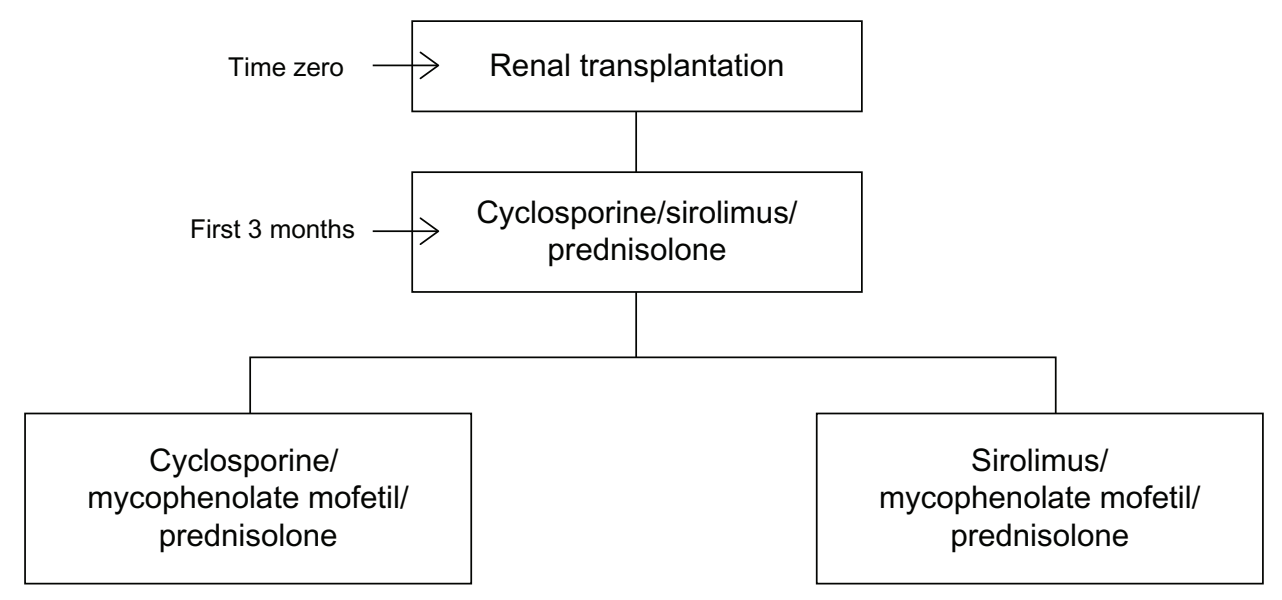

Figure I Schematic local randomized controlled trial protocol. Note: Data from? 
Table 2 Cost of immunosuppressive agents in SRL versus CsA based therapies in Iran (20II-20I2)

\begin{tabular}{|c|c|c|c|c|c|c|c|c|}
\hline $\begin{array}{l}\text { Immunosuppressive } \\
\text { drugs }\end{array}$ & $\begin{array}{l}\text { Dosage } \\
\text { form }\end{array}$ & $\begin{array}{l}\text { Dosage/dayl } \\
\text { patient }\end{array}$ & $\begin{array}{l}\text { Unit price } \\
\text { (IRR) }\end{array}$ & $\begin{array}{l}\text { Total cost/ } \\
\text { day/patient } \\
\text { (IRR) }\end{array}$ & $\begin{array}{l}\text { Number } \\
\text { of eligible } \\
\text { patients }\end{array}$ & $\begin{array}{l}\text { Duration } \\
\text { (days) }\end{array}$ & $\begin{array}{l}\text { Total cost } \\
\text { (IRR) }\end{array}$ & $\begin{array}{l}\text { Total cost } \\
\text { (US\$) }\end{array}$ \\
\hline \multicolumn{9}{|l|}{ CsA group } \\
\hline Cyclosporine (generic) & $\begin{array}{l}\text { Cap: } 25,100, \\
50 \mathrm{mg}\end{array}$ & $150 \mathrm{mg}$ qd & $\begin{array}{l}300,1,200 \\
1,500\end{array}$ & $5,742,000^{\mathrm{a}}$ & 2,200 & 270 & $\mathrm{I}, 550,340,000$ & 126,455 \\
\hline Mycophenolate mofetil & Cap: $500 \mathrm{mg}$ & $2 \mathrm{~g} \mathrm{qd}$ & 11,000 & 44,000 & 2,200 & 270 & $26,136,000,000$ & $2,|3|, 8||$ \\
\hline Total cost & & & & & & & $27,686,340,000$ & $2,258,266$ \\
\hline \multicolumn{9}{|l|}{ SRL group } \\
\hline SRL & Tab: I mg & $\begin{array}{l}\text { Loading dose: } \\
6 \mathrm{mg} \text { day I, } \\
\text { Maintenance } \\
\text { dose: } 2 \mathrm{mg} \text { qd }\end{array}$ & 10,000 & 20,000 & 2,200 & 270 & II,880,000,000 & 969,005 \\
\hline Mycophenolate mofetil & Cap: 500 mg & I g qd & 11,000 & 22,000 & 2,200 & 270 & $13,068,000,000$ & $1,065,905$ \\
\hline Total cost & & & & & & & $24,948,000,000$ & $2,034,910$ \\
\hline
\end{tabular}

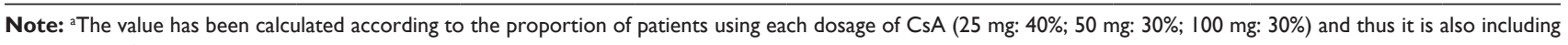
the number of patients.

Abbreviations: CsA, cyclosporine A; IRR, Iranian Rials; qd, once per day, every day; SRL, sirolimus; Cap, capsule; Tab, tablet.

\section{Analysis}

The model was constructed using Microsoft Excel ${ }^{\circledR} 2010$.

The total cost included both cost of immunosuppressive agents and cost of adverse events. The total cost difference between two scenarios was also reported in per-member per-month (PMPM) value, expressed in both IRR and US dollars (US\$). According to the official exchange price in the study year, 1 US\$ was equal to 12,260 IRR (Table 5 and Figure 2).
One-way sensitivity analysis was performed to determine robustness of the assessment through evaluation of changes in important variables. ${ }^{8,16}$ These variables included number of eligible patients per year, SRL market price, treatment duration, cost of immunosuppressive agents in the CsA based therapy, and costs of adverse events for SRL and CsA based regimens. Model parameters were varied by $75 \%$ from the base-case value, except treatment duration (which was from 90 to 720 days) and SRL

Table 3 Cost of adverse events per patient in renal transplantation therapy in Iran (20II-20I2)

\begin{tabular}{|c|c|c|c|c|c|c|c|}
\hline $\begin{array}{l}\text { Adverse } \\
\text { events/drugs }\end{array}$ & Dosage form & $\begin{array}{l}\text { Dosage/day/ } \\
\text { patient }\end{array}$ & $\begin{array}{l}\text { Number } \\
\text { per day }\end{array}$ & $\begin{array}{l}\text { Duration } \\
\text { (days) }\end{array}$ & $\begin{array}{l}\text { Unit price } \\
\text { (IRR) }\end{array}$ & $\begin{array}{l}\text { Total cost } / \\
\text { patient (IRR) }\end{array}$ & $\begin{array}{l}\text { Total cost } \\
\text { (US\$) }\end{array}$ \\
\hline \multicolumn{8}{|l|}{ CMV } \\
\hline \multirow[t]{2}{*}{ Ganciclovir } & For inj: $500 \mathrm{mg}$ & For treatment: & 2 & 7 & 250,000 & $3,500,000$ & 285 \\
\hline & & $\begin{array}{l}5 \mathrm{mg} / \mathrm{kg} \mathrm{q} 12 \text { hours } \\
\text { until treatment }\end{array}$ & & & & & \\
\hline Hospitalization & - & - & - & 7 & $1,600,000$ & $11,200,000$ & 914 \\
\hline \multicolumn{8}{|l|}{ Acute rejection } \\
\hline Methylprednisolon & For inj: $500 \mathrm{mg}$ & $250-1000 \mathrm{mg}$ & 1 & 7 & 200,000 & $\mathrm{I}, 400,000$ & 114 \\
\hline ATG & Inj: $250 \mathrm{mg} / 5 \mathrm{~mL}$ & $10-20 \mathrm{mg} / \mathrm{kg}$ & 4 & 7 & 550,000 & $15,400,000$ & 1,256 \\
\hline \multirow[t]{3}{*}{ Gancyclovir } & For inj: $500 \mathrm{mg}$ & For prophylaxis: & 1 & 7 & 250,000 & $\mathrm{I}, 750,000$ & 143 \\
\hline & & $5 \mathrm{mg} / \mathrm{kg}$ q 24 hours & & & & & \\
\hline & & until hospitalization & & & & & \\
\hline Hospitalization & - & - & - & 7 & $1,600,000$ & $11,200,000$ & 914 \\
\hline \multicolumn{8}{|l|}{ Graft failure } \\
\hline Dialysis & - & - & - & 10 times & 743,200 & $7,432,000$ & 606 \\
\hline Re-transplantation & - & - & - & - & $650 k^{a}$ & $39,000,000$ & 3,181 \\
\hline \multicolumn{8}{|l|}{ Hyperlipidemia } \\
\hline Atorvastatin & Tab: $10,20,40 \mathrm{mg}$ & $10-40 \mathrm{mg}$ & 1 & 270 & 1,100 & 297,000 & 24 \\
\hline \multicolumn{8}{|l|}{ Hypertension } \\
\hline Amlodipin & Tab: 5 mg & $5-10 \mathrm{mg}$ & 1 & 270 & 150 & 40,500 & 3 \\
\hline \multicolumn{8}{|l|}{ Thrombocytopenia } \\
\hline Plasmapheresis & - & - & - & 10 times & $1,300,000$ & $13,000,000$ & $\mathrm{I}, 060$ \\
\hline
\end{tabular}

Note: ak: IRR 60,000 (US\$)

Abbreviations: ATG, anti-thymocyte globulin; CMV, cytomegalovirus; inj, injection; Tab, tablet; IRR, Iranian Rials; q, once per day. 
Table 4 Total adverse events cost related to SRL versus CsA based therapies in renal transplantation therapy in Iran (20II-20I2)

\begin{tabular}{|c|c|c|c|c|c|}
\hline Adverse events & Probability & $\begin{array}{l}\text { Number of } \\
\text { patients }(2,200)\end{array}$ & $\begin{array}{l}\text { Unit cost } \\
\text { (IRR) }\end{array}$ & $\begin{array}{l}\text { Total cost } \\
\text { (IRR) }\end{array}$ & $\begin{array}{l}\text { Total cost } \\
\text { (US\$) }\end{array}$ \\
\hline \multicolumn{6}{|l|}{ CsA based therapy } \\
\hline CMV & 0.21 & 462 & $14,700,000$ & $6,791,400,000$ & 553,948 \\
\hline Acute rejection & 0.18 & 396 & $29,750,000$ & II,78I,000,000 & 960,930 \\
\hline Hyperlipidemia & 0.14 & 308 & 297,000 & $91,476,000$ & 7,461 \\
\hline Hypertension & 0.67 & $\mathrm{I}, 474$ & 40,500 & $59,697,000$ & 4,869 \\
\hline Graft failure & 0.105 & 231 & $46,432,000$ & $10,725,792,000$ & 874,861 \\
\hline Thrombocytopenia & 0.08 & 176 & $13,000,000$ & $2,288,000,000$ & 186,623 \\
\hline Total cost & & & & $31,737,365,000$ & $2,588,692$ \\
\hline \multicolumn{6}{|l|}{ SRL based therapy } \\
\hline CMV & 0.05 & 110 & $14,700,000$ & $\mathrm{I}, 617,000,000$ & $|3|, 892$ \\
\hline Acute rejection & 0.08 & 176 & $29,750,000$ & $5,236,000,000$ & 427,080 \\
\hline Hyperlipidemia & 0.44 & 968 & 297,000 & $287,496,000$ & 23,450 \\
\hline Hypertension & 0.78 & 1,716 & 40,500 & $69,498,000$ & 5,669 \\
\hline Graft failure & 0.075 & 165 & $46,432,000$ & $7,661,280,000$ & 624,900 \\
\hline Thrombocytopenia & 0.45 & 990 & $13,000,000$ & $12,870,000,000$ & $\mathrm{I}, 049,755$ \\
\hline Total cost & & & & $27,741,274,000$ & $2,262,747$ \\
\hline
\end{tabular}

Abbreviations: CMV, cytomegalovirus; CsA, cyclosporine A; IRR, Iranian Rials; SRL, sirolimus.

market price (which varied between prices before and after subsidization).

\section{Results}

\section{Base-case}

According to the model, almost 2,200 patients with ESRD underwent renal transplantation over the study year. The estimated expected 1-year cost of RTT for receiving CsA was almost 60 billion IRR (US\$4,850,000) versus 53 billion IRR (US\$4,300,000) for patients receiving SRL in their RTT regimen.

These figures included both the cost of immunosuppressive agents ( $47 \%$ of total costs) and the cost of adverse events ( $53 \%$ of total costs) in SRL and CsA based therapies (Figure 2). These costs corresponded to a cost savings of almost 7 billion IRR (US\$550,000) or 33,000 IRR (US\$3) PMPM for insurance organizations (Table 5).

\section{One-way sensitivity analysis}

Sirolimus market price is highly influential and could dramatically change the budget of the new strategy. The results showed that purchasing the drug at price up to almost US\$1.2-1.3 per tablet would result in cost savings for the payers (Figure 3). In addition, the cost of CsA based immunosuppressive therapy and its relative adverse events showed an essential role in the total cost difference. Regarding "number of patients", the results showed that, even with double the number of patients, the budget savings would also be almost twice greater than the base-case condition. In case of "treatment duration", by varying from 90 to 720 days, budget savings increased over time (Figure 4).

\section{Discussion}

Currently, Iran has one of the most successful transplantation programs in the Middle East. ${ }^{14}$ Notwithstanding renal

Table 5 Budget impact results of conversion from CsA to SRL in renal transplantation therapy for insurance organizations in Iran $(2011-2012)$

\begin{tabular}{|c|c|c|c|c|}
\hline $\begin{array}{l}\text { Budget components } \\
\text { (base-case) }\end{array}$ & $\begin{array}{l}\text { SRL based } \\
\text { therapy (IRR) }\end{array}$ & $\begin{array}{l}\text { CsA based } \\
\text { therapy (IRR) }\end{array}$ & $\begin{array}{l}\text { SRL based } \\
\text { therapy (US\$) }\end{array}$ & $\begin{array}{l}\text { CsA based } \\
\text { therapy (US\$) }\end{array}$ \\
\hline $\begin{array}{l}\text { Costs of immunosuppressive } \\
\text { therapy }\end{array}$ & $24,948,000,000$ & $27,686,340,000$ & $2,034,910$ & $2,258,266$ \\
\hline Costs of adverse events & $27,741,274,000$ & $31,737,365,000$ & $2,262,747$ & $2,588,692$ \\
\hline Total costs & $52,689,274,000$ & $59,423,705,000$ & $4,297,657$ & $4,846,958$ \\
\hline Total cost difference & $-6,734,431,000$ & & $-549,301$ & \\
\hline PMPM $^{a}$ & $-33,012$ & & -2.7 & \\
\hline
\end{tabular}

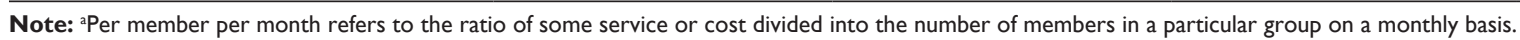

Abbreviations: CsA, cyclosporine A; IRR, Iranian Rials; PMPM, per member per month; SRL, sirolimus. 


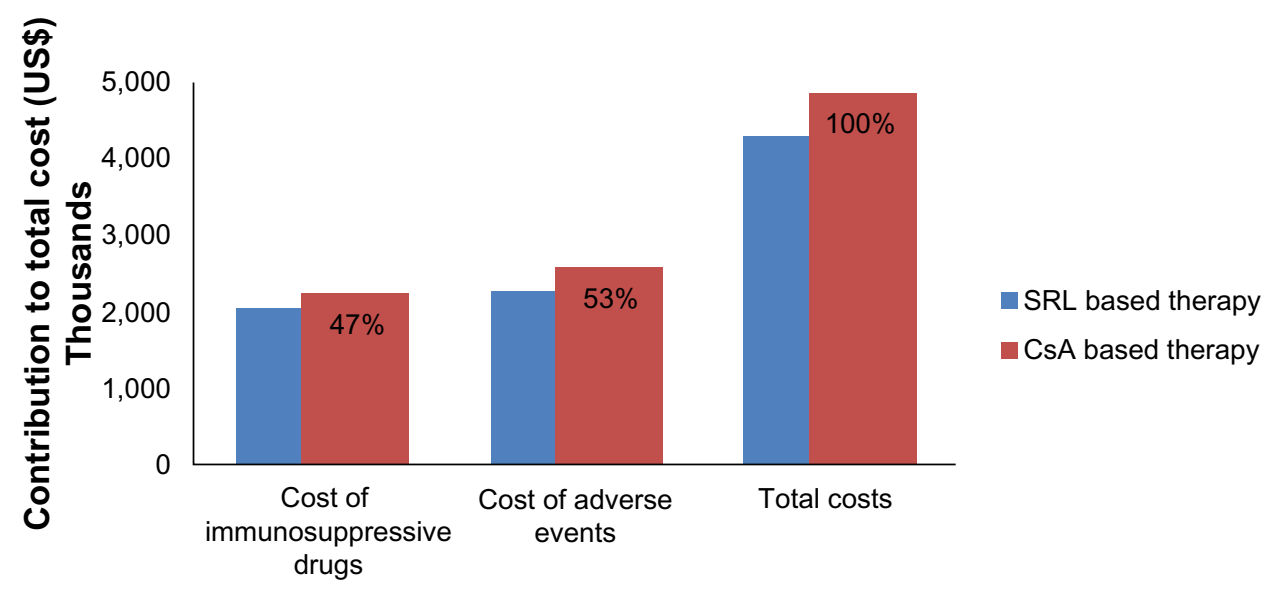

Figure 2 Budget impact of using SRL to replace the current conventional therapy with CsA in Iran (20II-20I2). Abbreviations: CsA, cyclosporine A; SRL, sirolimus.

replacement therapies (transplantation and hemodialysis), which have been grouped as special diseases and receive subsidy along with full reimbursement coverage in Iran, out-of-pocket expenditure is considerable for both of the aforementioned therapies. $\mathrm{MOH}$ as the main sponsor and, along with health insurance organizations, they cover almost all medicines and medical services included in the standard guidelines approved to be used in RTT.

However, regarding new expensive medicines and interventions, the cost of medical expenditures in renal replacement therapy is rapidly growing and becoming quite unaffordable for the government; therefore, out-of-pocket payment is dramatically increasing over time. In order to improve quality of care in terms of patient and graft survival, policy makers of insurance organizations should make a choice between newly introduced drugs, which are quite expensive, and current alternatives. ${ }^{15}$ This condition has led to an increased interest in health economic and financial evaluation of health care programs (cost effectiveness and BIA). ${ }^{16,17}$
The present study was the first BIA performed in Iran, introducing financial analyses as effective practical policy making tools to the Iranian health budget holders and was conducted in accordance with ISPOR standard guideline for good practice in BIA. It aimed to evaluate the financial consequence of adding mTOR inhibitors to the drug formulary of insurance organizations. ${ }^{8,17,18}$

Regarding different RTT strategies, in order to improve long-term graft survival and reduce CNI (CsA) toxicity, in recent years, attempts have been made to change immunosuppressive regimen by reducing CNI dosage or replacing them with other agents such as mTOR inhibitors. ${ }^{7}$

CsA reduction or replacement improves glomerular filtration rate (GFR) by $10 \%-20 \%$. In addition, studies have shown fewer cases of posttransplantation malignancies and CMV infections in patients receiving mTOR inhibitors compared to CsA.${ }^{6,7} \mathrm{~A}$ common approach is to advise a CNI-free regimen for maintenance therapy based on $\mathrm{mTOR}$ inhibitors (such as SRL and everolimus). ${ }^{1,19}$ Additionally, according to

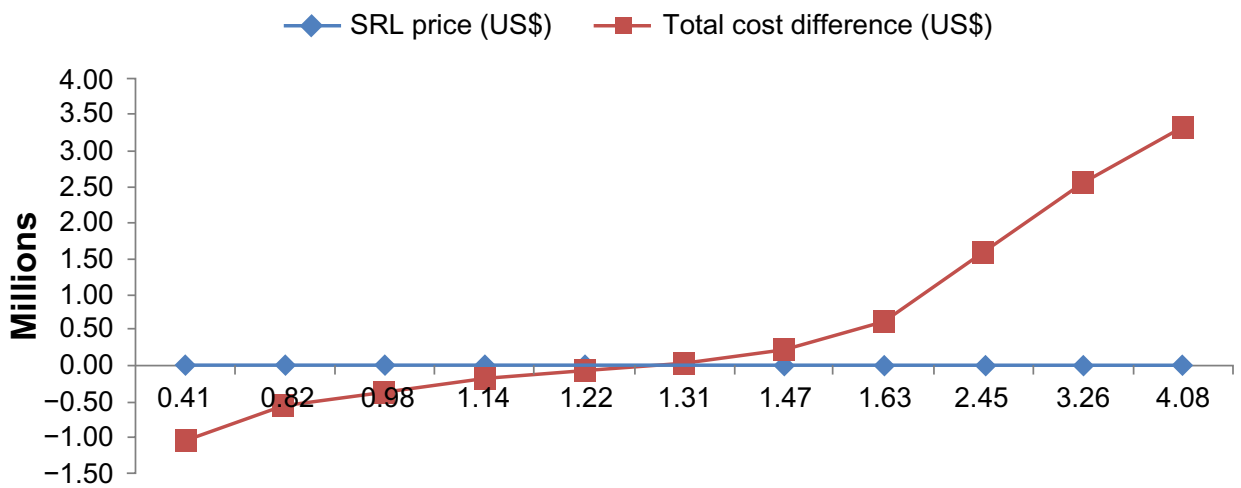

Figure 3 Sensitivity analyses results for SRL market price in Iran (20II-20I2). At a price between $\$ 1.22$ and $\$ 1.31$, the budget difference would be zero. Abbreviations: CsA, cyclosporine A; SRL, sirolimus. 
Total cost difference (US\$)

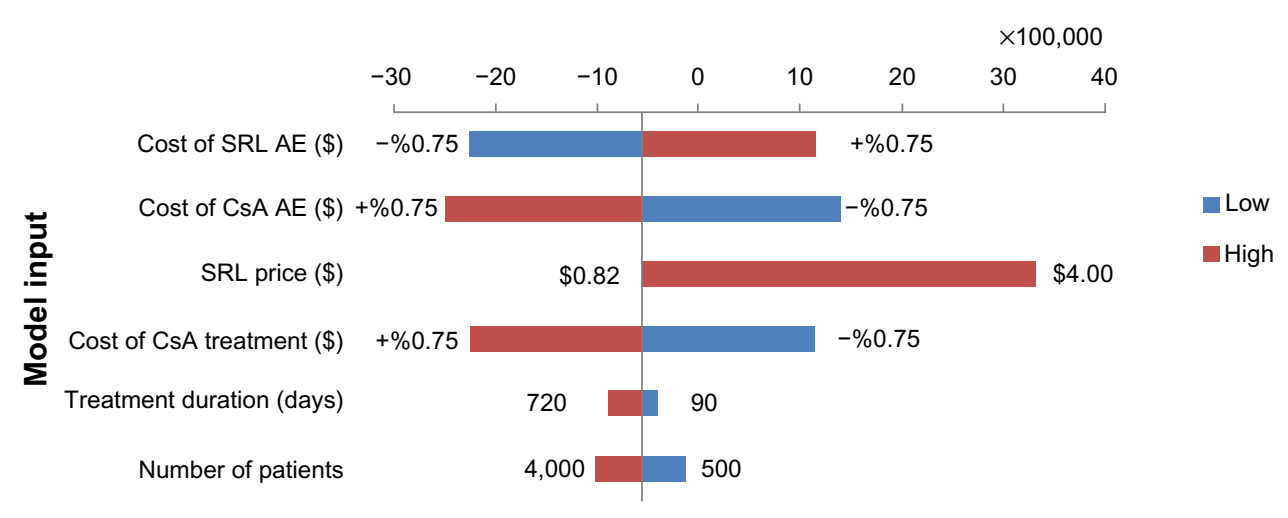

Figure 4 Sensitivity analyses: total BI difference between SRL and CsA based therapies (20II-20I2).

Notes: Values at the end of each bar indicate the change in Bl from the base-case or the possible lowest and highest values of that input (eg, in the SRL price and treatment duration).

Abbreviations: $A E$, adverse events; $B I$, budget impact; $C s A$, cyclosporine $A ; S R L$, sirolimus.

an economic evaluation study performed by McEwan et al in 2005, SRL was cost-effective compared to CsA for 10 to 20 years after renal transplantation in the UK. ${ }^{20}$

The present model was developed to estimate the financial effect (budgetary impact) of switching from CsA to SRL in RTT from the perspective of Iranian health insurance organizations. Based on the results of this study, considering 2,200 patients had their renal transplantation operation during the study year, the budget impact of conversion from CsA to SRL was minus 7 billion IRR (US\$550,000) or minus 33,000 IRR (US\$3) PMPM.

The results showed that, although SRL is relatively much more expensive than CsA, mainly because of the lower required doses of MMF (which is also quite expensive) and leading to fewer cases of graft failure, AR, and CMV infection over 12 months after renal transplantation, an SRL based regimen would be less costly compared to conventional CsA based therapies.

In addition, the analysis showed that, with an increase in the number of eligible patients and duration of treatment, the amount of cost saving would consequently increase. Also, considering the preventive effect of mTOR inhibitors in the incidence of posttransplantation malignancies (which commonly occur after 1-year posttransplantation), even more financial savings regarding less resource utilization (eg, hospitalization) are expected if a time horizon of more than 1 year is taken.

The regulated company price of SRL in Iran is almost 50,000 IRR (US\$4) per tablet; it has been currently subsidized by MOH at almost US\$3 per tablet and the rest (US\$1 per tablet) is paid by patients (out-of-pocket), which is not still quite affordable for many patients. It is recommended to health insurers to simply cover the rest of expenditures related to SRL with no additional expenses.

\section{Conclusion}

In the Iranian health care system, the $\mathrm{MOH}$ is responsible for the performance and also financing of the entire system through subsidization. For health care financing, there are also quasi-governmental health insurance organizations.

mTOR inhibitors as immunosuppressive agents are increasingly administered in RTT maintenance therapy and both patients and physicians are truly satisfied in practice. However, due to quite high out-of-pocket expenditure, many patients cannot afford to receive SRL and continue to use CsA.

To evaluate the financial consequence of adding mTOR inhibitors (SRL as a case) to insurance organizations' formulary, a BIA was conducted in the current study. According to the results of this analysis, the budget saving of converting from CsA to SRL was almost 33,000 IRR (US\$3) PMPM in Iran. Fewer cases of costly adverse events (graft failure, $\mathrm{AR}$, and $\mathrm{CMV}$ infection) along with lower required doses of MMF related to SRL based therapies were major reasons for budgetary savings of switching to SRL.

Insurance organizations in Iran could simply purchase the drug with a price range of almost US $\$ 0.82$ to US $\$ 1.30$ per tablet with almost no budgetary surplus in RTT. Moreover, with a higher number of patients as well as longer time horizon, savings would be much higher in value compared to the base case condition which is considered the preferred characteristics of drugs recommended for maintenance therapies. 


\section{Acknowledgments}

The authors would like to thank Dr Zahra Sahraee, Dr Hamid Reza Safikhani, Dr Keyvan Tajbakhsh, Dr Behrang Alipour, Dr Arash Foroutan, and Barakat Pharmaceutical Holding Company for their cooperation in this project. These findings are the result of work supported by Shahid Behashti School of Pharmacy.

\section{Disclosure}

The authors report no conflicts of interest in this work.

\section{References}

1. Han F, Wu J, Huang H, et al. Conversion from cyclosporine to sirolimus in chronic renal allograft dysfunction: a 4-year prospective study. Exp Clin Transplant. 2011;9(1):42-49.

2. Kahan B. Sirolimus: a new agent for clinical renal transplantation. Transplant Proc. 1997;29(1-2):48-50.

3. Groth CG, Bäckman L, Morales JM, et al. Sirolimus (rapamycin)based therapy in human renal transplantation: similar efficacy and different toxicity compared with cyclosporine. Sirolimus European Renal Transplant Study Group. Transplantation. 1999;67(7): 1036-1042.

4. Morath C, Arns W, Schwenger V, et al. Sirolimus in renal transplantation. Nephrol Dial Transplant. 2007;22(Suppl 8):viii61-viii65.

5. Webster AC, Lee VW, Chapman JR, Craig JC. Target of rapamycin inhibitors (sirolimus and everolimus) for primary immunosuppression of kidney transplant recipients: a systematic review and meta-analysis of randomized trials. Transplantation. 2006;81(9):1234-1248.

6. Büchler M, Caillard S, Barbier S, et al; SPIESSER Group. Sirolimus versus cyclosporine in kidney recipients receiving thymoglobulin, mycophenolate mofetil and a 6-month course of steroids. Am J Transplant. 2007;7(11):2522-2531.

7. Nafar M, Alipour B, Ahmadpoor P, et al. Sirolimus versus calcineurin inhibitor-based immunosuppressive therapy in kidney transplantation: a 4-year follow-up. Iran J Kidney Dis. 2012;6(4):300-306.
8. Mauskopf JA, Sullivan SD, Annemans L, et al. Principles of good practice for budget impact analysis: report of the ISPOR Task Force on good research practices - budget impact analysis. Value Health. 2007;10(5):336-347.

9. Mahdavi-Mazdeh M, Rouchi AH, Norouzi S, Aghighi M, Rajolani H, Ahrabi S. Renal replacement therapy in Iran. J Urol. 2007;4(2): 66-70.

10. Mehrdad R. Health system in Iran. JMAJ. 2009;52(1):69-73.

11. Hajizadeh M, Nghiem HS. Out-of-pocket expenditures for hospital care in Iran: who is at risk of incurring catastrophic payments? Int J Health Care Finance Econ. 2011;11(4):267-285.

12. MacDonald AS; RAPAMUNE Global Study Group. A worldwide, phase III, randomized, controlled, safety and efficacy study of a sirolimus/cyclosporine regimen for prevention of acute rejection in recipients of primary mismatched renal allografts. Transplantation. 2001;71(2):271-280.

13. Cravedi P, Ruggenenti P, Remuzzi G. Sirolimus for calcineurin inhibitors in organ transplantation: contra. Kidney Int. 2010;78(11):1068-1074.

14. Einollahi B. Kidney Transplantation in Iran. Iran J Med Sci. 2010; 35(1):1-8

15. Khosroshahi HT. Short history about renal transplantation program in Iran and the world: Special focus on world kidney day. J Nephropathology. 2012;1(1):5-10.

16. Nuijten MJ, Mittendorf T, Persson U. Practical issues in handling data input and uncertainty in a budget impact analysis. Eur J Health Econ. 2011;12(3):231-241.

17. Orlewska E, Mierzejewski P. Proposal of Polish guidelines for conducting financial analysis and their comparison to existing guidance on budget impact in other countries. Value Health. 2004;7(1):1-10.

18. Marshall DA, Douglas PR, Drummond MF, et al. Guidelines for conducting pharmaceutical budget impact analyses for submission to public drug plans in Canada. Pharmacoeconomics. 2008;26(6):477-495.

19. Flechner SM. Reviewing the evidence for de novo immunosuppression with sirolimus. Transplant Proc. 2008;40(Suppl 10):S25-S28.

20. McEwan P, Baboolal K, Conway P, Currie CJ. Evaluation of the costeffectiveness of sirolimus versus cyclosporin for immunosuppression after renal transplantation in the United Kingdom. Clin Ther 2005;27(11):1834-1846.
ClinicoEconomics and Outcomes Research

\section{Publish your work in this journal}

ClinicoEconomics \& Outcomes Research is an international, peerreviewed open-access journal focusing on Health Technology Assessment, Pharmacoeconomics and Outcomes Research in the areas of diagnosis, medical devices, and clinical, surgical and pharmacological intervention. The economic impact of health policy and health systems

\section{Dovepress}

organization also constitute important areas of coverage. The manuscript management system is completely online and includes a very quick and fair peer-review system, which is all easy to use. Visit http://www.dovepress.com/testimonials.php to read real quotes from published authors. 